\title{
Isolation of human umbilical cord blood-derived osteoprogenitor cells: a promising candidate for cell-based therapy for bone repair
}

\author{
Isolamento de células osteoprogenitoras derivadas de sangue de cordão umbilical humano: um \\ candidato promissor para terapias celulares para o reparo ósseo
}

\author{
Igor Iuco Castro-Silva ${ }^{1}$, Letícia de Oliveira Castro², Janaína José dos Santos Machado ${ }^{3}$, Maria Helena Alves \\ Nicola $^{3}$, José Mauro Granjeiro ${ }^{4}$
}

\begin{abstract}
Objective: The aim of this study was to evaluate the osteogenic potential of human umbilical cord blood-derived osteoprogenitor cells and to prove its applicability as a promising candidate for cell-based therapeutics for bone repair. Methods: Primary cultures of human umbilical blood cord adherent cells were expanded in vitro until passage 2 and seeded for osteodifferentiation study. Morphological (light microscopy), cytochemical (Von Kossa's method), and functional analyses (calcium level, alkaline phosphatase activity, and total protein content in cell culture) were carried out 7, 14, 21, and 28 days after the osteoinduction protocol. Results: The proliferative step showed colony-forming units in 7 days. After osteoinduction, cuboidal cellular morphology similar to osteoblasts at 14 days and mineralization nodules and biochemical changes (increased alkaline phosphatase level and calcium deposits) at 21 days confirmed the osteodifferentiation process. Conclusion: Cell culture of human umbilical blood cord is a reliable technique, constituting itself as an alternative source of osteoprogenitor cells for experimental needs. More animal tests and clinical trials must be carried out to validate its use and to establish quality control of future autologous or allogeneic cell-based therapy aimed at bone repair.
\end{abstract}

Keywords: Umbilical cord; Fetal blood; Cell culture; Osteogenesis; Tissue therapy; Bone regeneration

\section{RESUMO}

Objetivo: 0 objetivo deste estudo foi avaliar o potencial osteogênico de células osteoprogenitoras de sangue de cordão umbilical humano e provar sua aplicabilidade como candidato promissor para terapias celulares de reparo ósseo. Métodos: Culturas primárias de células aderentes de sangue de cordão umbilical humano foram expandidas in vitro até a passagem 2 e semeadas para estudo de osteodiferenciação. Análises morfológicas (microscopia de luz), citoquímicas (método de Von Kossa), e funcionais (dosagem de cálcio, atividade de fosfatase alcalina e conteúdo total de proteína na cultura celular) foram conduzidas em 7, 14, 21, e 28 dias após o protocolo de osteoindução. Resultados: A fase proliferativa demonstrou unidades formadoras de colônia em 7 dias. Após osteoindução, a morfologia celular cuboidal similar a osteoblastos em 14 dias e nódulos de mineralização e mudanças bioquímicas (aumento do nível de fosfatase alcalina e depósitos de cálcio) em 21 dias confirmaram 0 processo de osteodiferenciação. Conclusões: A cultura celular de sangue de cordão umbilical humano é uma técnica segura, constituindo-se uma fonte alternativa de células osteoprogenitoras para usos experimentais. Mais testes em animais e ensaios clínicos devem ser conduzidos para validar seu uso e estabelecer controle de qualidade de futuras terapias celulares autólogas ou alogênicas objetivando o reparo ósseo.

Descritores: Cordão umbilical; Sangue fetal; Cultura celular; Osteogênese; Terapia tecidual; Regeneração óssea

\section{INTRODUCTION}

Due to the increasing life expectancy of the population worldwide during the last decades, traumatic, degenerative, and chronic lesions of the

\footnotetext{
Study carried out the Department of Cell and Molecular Biology, Universidade Federal Fluminense - UFF, Niterói (RJ), Brazil.

'Department of Cell and Molecular Biology, Universidade Federal Fluminense - UFF, Niterói (RJ), Brazil.

${ }^{2}$ Faculdade de Química, Universidade Federal Fluminense - UFF, Niterói (RJ), Brazil.

${ }^{3}$ Cryopraxis Criobiologia - Rio de Janeiro (RJ), Brazil.

${ }^{4}$ Instituto Nacional de Metrologia, Padronização e Qualidade Industrial - DIPRO-INMETRO - Duque de Caxias (RJ), Brazil.

Corresponding author: Igor luco Castro-Silva - Rua Marques do Paraná, 303 - Prédio da Emergência - 4º Andar - Centro - CEP 24030-210, Niterói (RJ), Brazil - Tel.: 21-2629-9255 - E-mail: igoriuco@gmail.com Received on: July 7, 2011 - Accepted on: Nov 16, 2011

Conflict of interest: none
} 
musculoskeletal system have become an expressive socio-economic problem ${ }^{(1)}$. Despite the great progress in development of bone substitutes, there still is no ideal biomaterial capable of mimicking the natural proprieties of viable bone-forming cells ${ }^{(1,2)}$. In this way, bioengineering uses isolated cells or cells associated with carriers to substitute specific functions, aiming to create autologous or allogeneic hard tissues in the laboratory along with possible therapeutic agents ${ }^{(3,4)}$. Technical advances in cellular and molecular biology have made it possible to harvest osteoblast precursor cells (mesenchymal stem cells/MSC and osteoprogenitor cells/OPC) and differentiate them into bone tissue from a large variety of human tissues, such as bone marrow aspirate, cancellous bone, fat, muscle, periosteum, synovia, dental pulp, peripheral blood, dermis, and umbilical $\operatorname{cord}^{(1,4,5)}$.

Human umbilical cord blood (hUCB)-derived stromal cells tested for regenerative medicine purposes can be expanded ex vivo with no loss of their favorable biological properties such as self-renewal, adherence to plastic containers, surface antigen expression (CD105+/ CD45-) $)^{(6)}$, high plasticity (multi-differentiation into osteoblasts, chondroblasts, adipocytes, neurons, myoblasts, keratinocytes, endothelium, hepatocytes, and insulin-secreting cells $)^{(1,7-9)}$, immunomodulatory activity (suppression of cellular allograft rejection) $)^{(8,10)}$, and maintain viability after long-term storage by cryopreservation $^{(11)}$. The osteogenic capability of hUCB cells can be demonstrated in vitro by differentiation into active osteoblasts under adequate stimulation in a monolayer or three-dimensional calcium phosphatebased carrier ${ }^{(12,13)}$, and in vivo by ectopic bone in a subcutaneous site ${ }^{(13)}$, and enhanced bone repair of critical-size defects in rat calvarias ${ }^{(14)}$ and femurs ${ }^{(12)}$. However, the difficulties in producing cultures and great heterogeneity of results (morphological, growth rates, and differentiation potential data) of hUCB cells are remarkable ${ }^{(7,11,15)}$. Evidence of this behavior is a study with 25 donors of hUCB cells in which there was successful isolation in only 2 samples, with one a cell culture presenting normal proliferation and pluripotency and the other developing aneuploid lineages and decreased osteogenesis in vitro ${ }^{(16)}$.

\section{OBJECTIVE}

Whereas previously controversial outcomes pointed out the osteodifferentiation capability and the demand for a promising source in cell-based therapeutics for bone repair, the aim of this in vitro preliminary study was to perform a morphological, cytochemical, and functional evaluation of the osteogenic potential of hUCB-OPC.

\section{METHODS}

\section{Cell isolation and expansion}

This study was approved by the Ethics Committee in Human Being Research of the Universidade Federal Fluminense (CEP-UFF register \#56/07, Niteroi, Brazil) and performed with prior donor consent. A nurse team (Cryopraxis, Rio de Janeiro, Brazil) harvested full-term UCB from five healthy pregnant women (20-28 years) at ProMatre Hospital (Rio de Janeiro, Brazil).

All fresh UCB samples in 50mL Falcon tubes went through a cell separation process with Ficoll-PaquePlus (Histopaque $^{\mathrm{TM}}$ - GE Healthcare, Rio de Janeiro, Brazil; density $=1.077 \mathrm{~g} / \mathrm{mL}$ ) and centrifugation (671 x g, 30 minutes, at room temperature). Mononuclear cells were collected and resuspended in RPMI medium with Hepes and 5\% albumin, transferred at cold temperature to the lab, and processed until 24 hours after birth. There was an additional centrifugation (671 x g, 15 minutes, at room temperature) and resuspension in $\alpha$-MEM with $2 \mathrm{mM}$ L-glutamine, $20 \%$ fetal bovine serum (Gibco-Invitrogen, São Paulo, Brazil), and $100 \mu \mathrm{g} / \mathrm{mL}$ gentamicin (Sigma-Aldrich, São Paulo, Brazil), and storage in $25 \mathrm{~cm}^{2}$ plastic containers (Corning, São Paulo, Brazil) at $37^{\circ} \mathrm{C}, 5 \% \mathrm{CO}_{2}$ pressure, and $95 \%$ wet atmosphere. Every 2 days, culture medium containing non-adherent cells was carefully removed and centrifuged; the pellet was mixed to fresh complete medium and the cell suspension returned to its former recipient. Approximately 1 week after incubation, well-defined adherent and fibroblast-like colonies appeared. The subculture occurred in about of $80 \%$ of the monolayer confluence at 28 days, when the cell culture was detached using $0.25 \%$ trypsin-EDTA (Sigma-Aldrich, São Paulo, Brazil). After 14 days, the cells were nearly confluent and a new subculture was performed until osteoinduction. Use of the Trypan blue-exclusion method (Sigma-Aldrich, São Paulo, Brazil) and the Neubauer counting chamber allowed analysis of cell viability, as follows: $N C \times D \times 10^{4} / Q$, where $N C=$ number of viable cells, $D=$ dilution of sample, $Q=$ quarters of Neubauer-counting chamber.

\section{Experimental design for osteoinduction}

After the expansion, hUCB-MSC $\left(1.0 \times 10^{5}\right.$ cells $\left./ \mathrm{mL}\right)$ at passage 2 were seeded into 24 -well plates (Corning Inc., California, United States) in an $\alpha$-MEM enriched with $20 \%$ fetal bovine serum. After 96 hours with $80 \%$ of maximum confluence, the cells were treated with well-defined osteogenic solution ${ }^{(1)}$ containing $20 \mathrm{nM}$ of dexamethasone (Sigma-Aldrich, São Paulo, Brazil), $50 \mu \mathrm{g} / \mathrm{mL}$ of ascorbic acid (Sigma-Aldrich, 
São Paulo, Brazil), and $10 \mathrm{mM}$ of $\beta$-glycerophosphate (Sigma-Aldrich, São Paulo, Brazil) (DAG) $)^{(1,6)}$. The osteogenic media was changed every 2 days. These cells were monitored by well-defined treatment periods for osteoblast differentiation in vitro ${ }^{(1)}$ at 7 , 14, 21, and 28 days.

For every five hUCB samples, five independent experiments (morphological analysis, cytochemical detection of mineralization nodules, calcium dosage, alkaline phosphatase activity, and total protein content) were carried out according to the corresponding four treatment periods, using three replicates each $(n=300)$.

\section{Morphological analysis}

Photomicrographs were obtained using an inverted microscope (phase contrast), LabomedTCM 400 (Feldmann Wild Leitz, Manaus, Brazil), and documented with a Canon Powershot A310 3.2 Mp digital camera (Canon, California, United States).

\section{Cytochemical detection of mineralization nodules}

To detect the capacity of hUCB in mineralizing extracellular matrix in the form of mineralized nodules, von Kossa staining was used. Briefly, the layer of cells was fixed by $10 \%$ formalin (10 minutes) and rigorously washed with PBS (10 minutes). Next, $5 \%$ silver nitrate was added, followed by exposure to ultraviolet light for 60 minutes The layer of cells was again washed with PBS (three times), immersed in 5\% sodium thiosulphate for 3 minutes, and stained with $0.5 \%$ safranin. Cytochemical analysis was performed using an inverted microscope (phase contrast), LabomedTCM 400 (Feldmann Wild Leitz, Manaus, Brazil), and photomicrographs were documented with a Canon Powershot A310 3.2 Mp digital camera (Canon, California, United States).

\section{Calcium dosage}

A commercial kit (Enzipharma, São Paulo, Brazil) was used to quantify the presence of calcium in the supernatant (or free calcium) or pellet (trapped calcium) of the cell culture. In each experimental period, the culture medium (supernatant) or layer of cells (pellet) was collected and frozen at $-20^{\circ} \mathrm{C}$ in microtubes (Eppendorf ${ }^{\mathrm{TM}}$, Campinas, Brazil). Then the pellet, the layer containing cells plus extracellular matrix, was digested in $0.5 \mathrm{M} \mathrm{HCl}$ during 18 hours at $4^{\circ} \mathrm{C}$ and frozen until time of dosage. Samples were read in the microplate-reader and spectrophotometer (Beckman Coulter, California, United States) at the
$560 \mathrm{~nm}$ wavelength using calcium as a reference standard. The machine was blanked using distilled water (for medium) and $\mathrm{HCl} 0.5 \mathrm{M}$ (for the pellet).

\section{Alkaline phosphatase activity}

In each experimental period, the culture medium was collected $(1 \mathrm{~mL})$, transferred to a microtube (Eppendorf $^{\mathrm{TM}}$, Campinas, Brazil) and frozen at $-20^{\circ} \mathrm{C}$ for later determination of alkaline phosphatase activity. Briefly, aliquots of $100 \mu \mathrm{L}$ were added to the reaction medium for the determination of enzyme activity using a commercial kit (Enzipharma, São Paulo, Brazil). After 10 minutes of incubation at $37^{\circ} \mathrm{C}, 100 \mu \mathrm{L}$ of $1.0 \mathrm{M} \mathrm{NaOH}$ were added, stopping the reaction. Optical density was measured in the microplate-reader spectrophotometer (Beckman Coulter, California, United States) at a wavelength of $405 \mathrm{~nm}$.

\section{Total protein}

Total protein content in cell culture supernatant was determined in all samples using Bradford's method as proposed by the manufacturer (Bio-Rad kit ${ }^{\mathrm{TM}}$ - BioRad, California, United States). The culture medium was collected $(1 \mathrm{~mL})$, transferred to a microtube (Eppendorf $^{\mathrm{TM}}$, Campinas, Brazil) and frozen at $-20^{\circ} \mathrm{C}$ for later determination of total protein. Briefly, aliquots of $20 \mu \mathrm{L}$ were added to the reaction medium $(1 \mathrm{~mL})$ for the determination of soluble protein concentration. After 5 minutes of incubation at room temperature, the reaction was interrupted and optical density was measured in the microplate-reader spectrophotometer (Beckman Coulter, California, United States) at a wavelength of $405 \mathrm{~nm}$.

\section{Statistical analysis}

The biochemical results were shown on graphs representing the mean \pm standard error of the mean. Data from each assay was assessed by InStat 3.10 software (GraphPadInc, California, United States) using the statistical Kruskal-Wallis test $(\mathrm{p}<0.05)$ and Dunn's Multiple Comparison Test as post test.

\section{RESULTS}

\section{Morphological analysis}

The primary hUCB cell culture was initially characterized as composed of round-shaped, mononuclear cells (Figure 1A) with delayed adhesion on plastic containers at 7 days during the in vitro expansion (Figures 1B and 1C), and reached 
confluence in 28 days, adopting a fibroblast-like, mesenchymal phenotype (Figure 1D). Subculturing of hUCB cells decreased by half the time the cell confluence for 14 days. After the seeding procedure for the osteogenesis assay, $80 \%$ confluence was obtained only in 4 days, confirming the delayed expansion of these immature cells derived from hUCB. Some stroma-adherent colony-forming units (CFU) (Figure 1B) were evident after 7 days in expansion and might suggest nests of clonogenic mesenchymal stem cells. Phenotypic change from fibroblast-like or

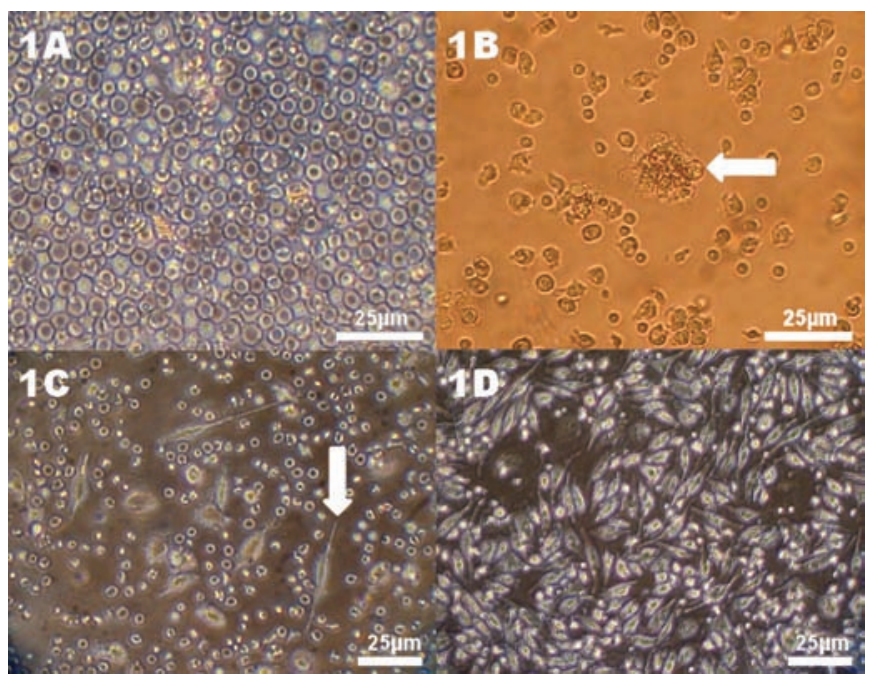

Figure 1. Proliferative step in primary culture of hUCB cells. (A) Non-adherent round-shaped, mononuclear cells in 1 day, (B) Adherent colony-forming unit (black arrow) in 7 days, (C) Adherent fibroblast-like cells (white arrow) in 7 days and (D) Confluent cell monolayer, 28 days

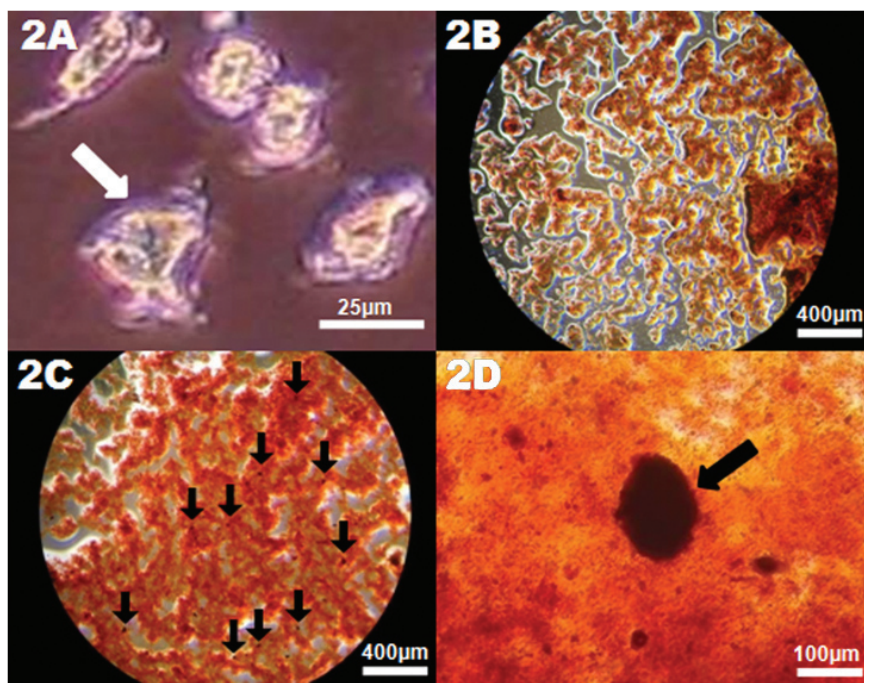

Figure 2. Morphological analysis of the osteodifferentiation process of hUCB-OPC. (A) Cells with cuboidal shape (white arrow) after 14 days in contact with osteoinductive medium. (B-D) Von Kossa staining, without bone nodules formation in 14 days (B) or demonstrating multiple presence of small mineralization nodules (black arrows) in 21 days (C-D) undifferentiated cells (Figures 1C-1D) to polyedric or cuboidal morphology similar to osteoblasts (Figure 2A) occurred after 14 days of osteoinduction.

\section{Cytochemical analysis}

Osteoinduction in hUCB cell culture until 14 days (Figure 2B) did not exhibit positive signs of biomineralization. However, multiple small and blackstained mineralized nodules were observed by the von Kossa method after 21 days of osteoinduction in the hUCB-OPC culture (Figures $2 \mathrm{C}$ and 2D), following the increase in their number and size in 28 days.

\section{Functional analysis}

All the biochemical findings helped to corroborate the osteodifferentiation process and no significant differences were observed among the donors of hUCB cells for each treatment period ( $p>0.05)$. In comparison with the pure osteoinductive medium, the calcium level in the cell culture supernatant declined in 21 days (absorbance: $0.59 \pm 0.02, \mathrm{p}<0.05$ ), and more significantly in 28 days (absorbance: $0.53 \pm 0.05$, $\mathrm{p}<0.01$ ) (Figure 3A). On the other hand, the calcium level in the pellet represented by adherent cells and their extracellular matrix increased during the same period of 21 days (absorbance: $0.19 \pm 0.01, \mathrm{p}<0.05$ ) and reached the greatest value in 28 days compared to all experimental periods (absorbance: $0.28 \pm 0.01$, $\mathrm{p}<0.001$ ) (Figure 3B). Alkaline phosphatase activity had significant growth during the period from 21 days
3A

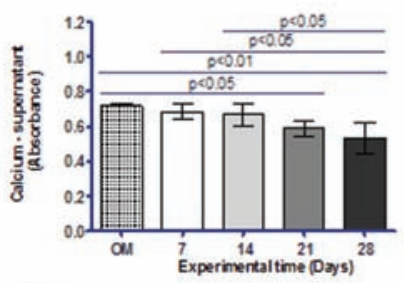

3C

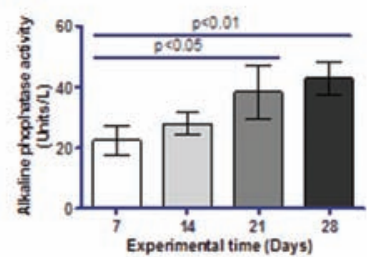

3B

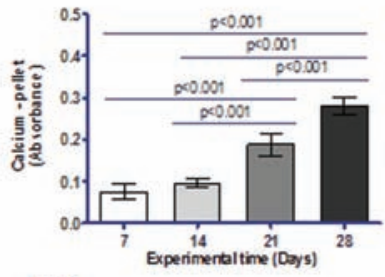

3D

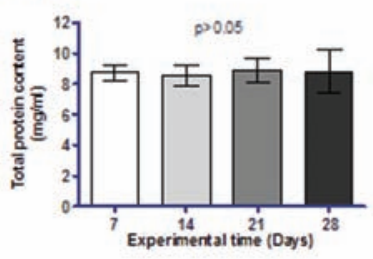

Figure 3. Functional analysis of the osteodifferentiation process of hUCBOPC at 7, 14, 21 and 28 days. (A) Calcium level in cell culture supernatant in comparison with osteogenic medium, (B) Calcium level in cell culture pellet, (C) Alkaline phosphatase activity and (D) Total protein content in cell culture supernatant 
$(38.31 \pm 4.44 \mathrm{U} / \mathrm{L}, \mathrm{p}<0.05)$ to 28 days $(42.88 \pm 2.75 \mathrm{U} / \mathrm{L}$, $\mathrm{p}<0.01$ ) (Figure 3C). Total protein content was unchanged during the experimental periods in all hUCBOPC samples $(p>0.05)$ (Figure 3D), thus highlighting the particular expression of alkaline phosphatase in the in vitro osteogenesis.

\section{DISCUSSION}

Strong efforts have been made to introduce cell therapeutics as an option for patients with bone defects. Harvesting of UCB cells, a rich source of hematopoietic stem cells with practical and ethical benefits, represents an alternative non-invasive method for bone marrow-MSC collection $^{(3,11,16)}$, although it also exhibits specific challenges for bone regeneration ${ }^{(1)}$.

HUCB cell cultures are notoriously heterogeneous due to the quality of laboratory preparations including fresh tissue samples, cell culture media, presence of animal sera, cytokines, cell density, number of passages upon culture, and osteogenic induction ${ }^{(9,11,15)}$. Optimal conditions in hUCB cell cultures include a minimum aspirate volume of $33 \mathrm{~mL}$, time from collection to isolation of less than 15 hours, and high initial cell concentration $\left(1.0 \times 10^{6}-10^{8}\right.$ cells $^{(4,5,17)}$. Initial co-culture of hematopoietic and MSC derived from hUCB is performed (osteoprogenitor cellsand adherent cell populations appear after 3 to 5 weeks in vitro $)^{(4,11,18)}$. Clonogenicity of hUCB cells is determined by the presence of $\mathrm{CFU}^{(4)}$ and the frequency of the MSC range from 0 to 2.3 clones per $1.0 \times 10^{8}$ cells $^{(5)}$. The primary culture of hUCB wasdelayed in reaching confluence, from 34 days (passage 1) to 55 days (passage 1-2), due to the presence of more immature cells ${ }^{(1)}$. Once established, the proliferation kinetics of UCB cells did not differ significantly from that of bone marrow, resulting from 20 population doublings within 8 passages $^{(5)}$ to more than 50 population doublings after 15 weeks $^{(4)}$, as well as its multilineage capacity ${ }^{(3,5,16)}$. Different culture media including $\alpha$-MEM, DMEM, and MSCGM (SingleQuot growth supplement), enriched with 10 to $15 \%$ fetal calf serum or human platelet lysate and osteogenic mixture (DAG) in combination with or without BMP-2 $\left(10^{-7} \mathrm{M}\right)$ can lead to a high amount of Cbfa1/Runx2, collagen $I^{(1,6,19)}$, alkaline phosphatase, mineralized extracellular matrix ${ }^{(1,6,7,19)}$, osteocalcin, osteonectin, osteopontin, vimentin, bone sialoprotein, fibroblastic growth factor-2, and vascular endothelial growth factor among other bone markers in UCB cell cultures over 21 days of osteoblastic differentiation $^{(1,6)}$. Early exposure to a medium with osteogenic supplements and human plasma markedly increased the stromal cell growth and the rate of osteogenic differentiation, suggesting that full-term UCB may act as an appropriate source of OPC, which will significantly impact the development of autologous tissue-engineered bone constructs ${ }^{(2)}$. These protocols corroborate our good experience using an adequate sample volume (40 to $50 \mathrm{~mL}$ of hUCB), culture medium (RPMI for initial co-culture of hematopoietic and mesenchymal cells and $\alpha$-MEM with $20 \%$ fetal bovine serum for mesenchymal and OPC proliferation), and DAG in the osteoinduction step. Moreover, the morphological similarity of hUCB cells that had undergone cryopreservation for 0.1-5 years with fresh samples ${ }^{(7,11)}$ and their routine storage in biological banks could highlight the immediate clinical value of $\mathrm{hUCB}^{(20)}$.

However, cell isolation and expansion have been most successful using bone marrow $(10: 10)^{(9)}$, adipose tissue $(10: 10)^{(21)}$, and umbilical cord matrix (UCM) samples $\left[8: 8^{(9)}\right.$ or $\left.10: 10^{(20)}\right]$, in comparison with variable rates in UCB samples $\left[10 \%{ }^{(20)}, 46 \%{ }^{(4)}\right.$, or $\left.63 \%{ }^{(5,21)}\right]$. CFU frequency is lowest in UCB, but UCB-MSC can be cultured for the longest time and shows the highest proliferation capacity ${ }^{(21)}$ due to the immaturity of cells from newborns ${ }^{(1)}$, thus becoming a good substitute for bone marrow, which has a highly invasive donation procedure and declines in MSC number and differentiation potential with increasing age $\mathrm{e}^{(1,3,10,21)}$. Furthermore, UCB-MSC expanded in vitro retain low immunogenicity and an immunomodulatory effect in lymphocytes and mature dendritic cells, which is ideal for allogeneic applications in the future ${ }^{(10)}$.

Our results, based on good laboratory practices and a proficient protocol, could suggest the presence of CFU during the expansion step of hUCB cells and accompany their well-defined osteodifferentiation process in vitro. This particular biological behavior could be explained by cuboidal cell morphology resembling osteoblasts in 14 days $^{(1)}$ and the presence of extracellular bone matrix over 21 days, detected in cytochemical analysis with typical mineralization nodules as well as osteoblast cultures ${ }^{(1,6,19)}$ and in functional analysis with the maintenance of total protein content, suggesting the establishment of cell growth and direction towards a differentiation process, increased expression of alkaline phosphatase ${ }^{(13,19)}$, and changes in calcium metabolism (decreased level in the supernatant and increased deposit in pellets) during the osteoinduction $\operatorname{step}^{(1,14)}$. In this way, as an archetypical source of osteoprogenitor cells that can be harvested, enriched, and expanded in vitro, hUCB have been reported to be of significance for regenerative medicine ${ }^{(11,15)}$. 
Multiple pre-clinical studies tested hUCB in cellbased therapeutics for bone repair, but rare clinical trials have been carried out ${ }^{(15)}$. hUCB cells can attach and spread efficiently on calcium phosphates (hydroxyapatite/tricalcium phosphate) ${ }^{(2)}$, porous collagen $^{(3,6)}$, collagen/tricalcium phosphate $^{(12)}$,or poly(lactic-glycolic acid)/hydroxyapatite ${ }^{(13)}$-based scaffolds. Additionally, they can continue to osteoblastic differentiation ${ }^{(2,3,6)}$, promote ectopic osteogenesis $^{(13)}$, or improve bone repair in rat calvarial defects up to $78 \%$ at 12 weeks $^{(14)}$. The ability of hUCB cells to differentiate into mature osteoblasts when cultured inside human plasma clots suggests their potential application in orthopedic surgery ${ }^{(3)}$. Interestingly, one recent clinical trial carried out in adult patients with traumatic bone nonunion demonstrated that auto-iliac bone transplantation had statistically significant differences with a cellbased treatment (allogeneic hUCB-stromal cells conjugated to autogenic platelet-rich plasma and demineralized bone powder) that exhibited the greatest and fastest tibiofemoral repair, decreasing by half the time of bone union (6 months). In this way, the specific role of cell therapy with hUCB in bone repair and the bioactivity related to its auxiliary carriers must be better investigated ${ }^{(17)}$.

Considering issues of safety, availability, transplant methodology, rejection, and side effects, it is contended that therapeutics using hUCB cells provide a reliable repository of early precursor cells, and the confirmed presence of OPC in this work encourages its use as a potential source in cell therapy protocols for bone defects. The elucidation of nonhematopoietic applications for UCB will facilitate the development of relevant pioneering cell therapy ${ }^{(8)}$. Furthermore, the study of hUCB-OPC may provide new cellular research models for understanding human malformations and genetic disorders, as well as the possibility of testing the effects of different therapeutic drugs ${ }^{(20)}$.

\section{CONCLUSION}

We could conclude that the cell culture of hUCB is a reliable technique, establishing itself as an alternate source of osteoprogenitor cells for experimental needs. More animal tests and clinical trials must be carried out to validate its use and to establish quality control of future autologous or allogeneic cell-based therapeutics aimed towards bone repair.

\section{ACKNOWLEDGEMENTS}

Our special thanks to Mari Cleide Sogayar, phD, director of NUCEL (Cell Therapy Center, Universidade de São Paulo) for her scientific collaboration, and to Cryopraxis, Silvestre Labs, FAPERJ, FINEP, CAPES and CNPq (CT-Saude, \#55.2644/2005-6) for the financial support.

\section{REFERENCES}

1. Jäger M, Zilkens C, Bittersohl B, Krauspe R. Cord Blood - An alternative source for bone regeneration. Stem Cell Rev. 2009;5(3):266-77.

2. Hutson EL, Boyer S, Genever PG. Rapid isolation, expansion, and differentiation of osteoprogenitors from full-term umbilical cord blood. Tissue Eng. 2005;11(9-10):1407-20.

3. Barachini S, Trombi L, Danti S, DAlessandro D, Battolla B, Legitimo A, et al. Morpho-functional characterization of human mesenchymal stem cells from umbilical cord blood for potential uses in regenerative medicine. Stem Cells Dev. 2009;18(2):293-305.

4. Reinisch A, Bartmann C, Rohde E, Schallmoser K, Bjelic-Radisic V, Lanzer G, et al. Humanized system to propagate cord blood-derived multipotent mesenchymal stromal cells for clinical application. Regen Med. 2007;2(4):371-82.

5. Bieback K, Kern S, Klüter H, Eichler H. Critical parameters for the isolation of mesenchymal stem cells from umbilical cord blood. Stem Cells. 2004;22(4):625-34.

6. Jäger M, Krauspe R. Antigen expression of cord blood derived stem cells under osteogenic stimulation in vitro. Cell Biol Int. 2007;31 (9):950-7.

7. Kögler G, Sensken S, Wernet P. Comparative generation and characterization of pluripotent unrestricted somatic stem cells with mesenchymal stem cells from human cord blood. Exp Hematol. 2006;34(11):1589-95.

8. Arien-Zakay $H$, Lazarovici $P$, Nagler A. Tissue regeneration potential in human umbilical cord blood. Best Pract Res Clin Haematol. 2010;23(2):291-303

9. Zeddou M, Briquet A, Relic B, Josse C, Malaise MG, Gothot A, et al. The umbilical cord matrix is a better source of mesenchymal stem cells (MSC) than the umbilical cord blood. Cell Biol Int. 2010;34(7):693-701.

10. Wang M, Yang Y, Yang D, Luo F, Liang W, Guo S et al. The immunomodulatory activity of human umbilical cord blood derived mesenchymal stem cells in vitro. Immunology. 2009;126(2):220-32.

11. Lee MW, Choi J, Yang MS, Moon YJ, Park JS, Kim HC, et al. Isolation of Mesenchymal stem cells from cryopreserved human umbilical cord blood. Biochem Biophys Res Commun. 2004;320(1):273-8.

12. Jäger M, Degistirici 0 , Knipper $A$, Fischer J, Sager M, Krauspe R. Bone healing and migration of cord blood-derived stem cells into a critical size femoral defect after xenotransplantation. J Bone Miner Res. 2007;22(8):1224-33.

13. Kang JM, Kang SW, La WG, Yang YS, Kim BS. Enhancement of in vivo bone regeneration efficacy of osteogenically undifferentiated human cord blood mesenchymal stem cells. J Biomed Mater Res A. 2010;93(2):666-72.

14. Liu GP, Li YL, Sun J, Cui L, Zhang WJ, Cao YL. Repair of calvarial defects with human umbilical cord blood derived mesenchymal stem cells and demineralized bone matrix in athymic rats. Zhonghua Zheng Xing Wai Ke Za Zhi. 2010;26(1):34-8.

15. Ho AD, Wagner W, Franke W. Heterogeneity of mesenchymal stromal cell preparations. Cytotherapy. 2008;10(4):320-30. 
16. Manca MF, Zwart I, Beo J, Palasingham R, Jen LS, Navarrete R et al. Characterization of mesenchymal stromal cells derived from full-term umbilical cord blood. Cytotheraphy. 2008;10(1):54-68.

17. Qu Z, Mi S, Fang G. Clinical study on treatment of bone nonunion with MSCs derived from human umbilical cord. Zhongguo Xiu Fu Chong Jian Wai Ke Za Zhi. 2009;23(3):345-7.

18. Kedong S, Xiubo F, Tianqing L, Macedo HM, LiLi J, Meiyun F, et al. Simultaneous expansion and harvest of hematopoietic stem cells and mesenchymal stem cells derived from umbilical cord blood. J Mater Sci Mater Med. 2010;21(12):3183-93.
19. Hildebrandt C, Büth $H$, Thielecke $H$. Influence of cell culture media conditions on the osteogenic differentiation of cord blood-derived mesenchymal stem cells. Ann Anat. 2009;191(1):23-32.

20. Secco M, Zucconi E, Vieira NM, Fogaça LL, Cerqueira A, Carvalho MD, et al. Multipotent stem cells from umbilical cord: cord is richer than blood! Stem Cells. 2008;26(1):146-50.

21. Kern S, Eichler H, Stoeve J, Klüter H, Bieback K. Comparative analysis of mesenchymal stem cells from bone marrow, umbilical cord blood, or adipose tissue. Stem Cells. 2006;24(5):1294-301. 